GAO Report to Congressional Requesters

September 2003

\title{
HEAD START
}

Curriculum Use and

Individual Child

Assessment in

Cognitive and

Language

Development

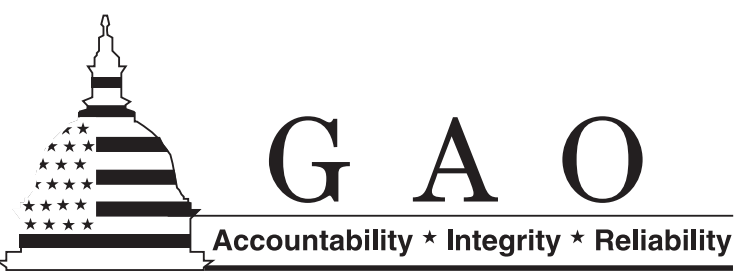




\section{Contents}

\section{Letter}

\section{Abbreviations}

FACES Family and Child Experiences Survey

HHS Department of Health and Human Services

This is a work of the U.S. government and is not subject to copyright protection in the United States. It may be reproduced and distributed in its entirety without further permission from GAO. However, because this work may contain copyrighted images or other material, permission from the copyright holder may be necessary if you wish to reproduce this material separately. 
September 12, 2003

The Honorable George Miller

Ranking Minority Member

Committee on Education and the Workforce

House of Representatives

The Honorable Dale E. Kildee

Ranking Minority Member

Subcommittee on Education Reform

Committee on Education and the Workforce

House of Representatives

To enhance Head Start's contribution to the school readiness of children from low-income families, the 1998 amendments to the Head Start Act provided for updating the Head Start performance standards to ensure that when children leave the program, they have the basic skills needed to start school. ${ }^{1}$ Head Start's performance standards for education and early childhood development require that the programs' curricula support each child's cognitive and language development, including emergent literacy skills. In preschool children, cognitive and language development refers to the fundamental abilities needed to reason and to speak a language. Skills in emergent literacy are the precursors to reading, such as learning the letters of the alphabet. The curriculum Head Start programs use must meet the definition for a written curriculum in Head Start's performance standards. Programs have the option of developing their own curriculum, using a curriculum developed locally or by the state education agency, and adopting or adapting a model developed by an educational publisher.

Programs also may use teacher mentoring and individual child assessment to help implement the curriculum.

As reauthorization of Head Start approached, you asked us to answer these questions about Head Start programs' efforts to prepare children for school:

${ }^{1}$ Pub. L. 105-285, Title I, Sec. 108 (amending sec. 641A of the Head Start Act). 
1. To what extent have Head Start programs made progress in meeting performance standards for cognitive and language development since they took effect in January 1998 ?

2. To what extent has local Head Start programs' use of curricula changed since the performance standards for children's cognitive and language development were issued?

3. To what extent have local Head Start programs used teacher mentoring and individual child assessments to support curriculum planning?

To determine what progress has been made in meeting the new standards, we used data from Head Start's compliance reviews. We analyzed the percentage of Head Start programs that met overall performance standards for curriculum and the percentage that met seven specific performance standards for cognitive and language development. To examine local Head Start programs' use of curricula, mentoring, and individual child assessments, we analyzed data from the Department of Health and Human Services' (HHS) Family and Child Experiences Survey (FACES). FACES is a series of longitudinal surveys of nationally representative samples of Head Start children. ${ }^{2}$ We used data from the spring 1998 and fall 2000 teacher interviews, which contained information about types of Head Start curricula and classroom activities, the percentage of teachers who received mentoring visits, the percentage of Head Start children who received individual child assessments and how teachers used the assessment information. Although limitations in the FACES data did not allow us to determine change in curricula and classroom activities over time, the data did permit us to describe Head Start curricula and classroom activities at two points in time. Information on mentoring and individual child assessment was available only for fall 2000. We also interviewed officials in 9 of 10 HHS regional offices about Head Start programs' curriculum practices and analyzed HHS' 2002 Program Information Report data on curricula. The Program Information Report contains basic information about Head Start programs' operating characteristics and services. All Head Start and Early Head Start programs

${ }^{2}$ Nicholas Zill, et al., Head Start FACES (2000): A Whole-Child Perspective on Program Performance, Fourth Progress Report, A report prepared for Child Outcomes Research and Evaluation, Office of Planning, Research and Evaluation, Administration for Children and Families, Department of Health and Human Services, May 2003, provides additional details about the FACES sample design. 
are required to submit data for the Program Information Report annually. We conducted our work between February and June 2003 in accordance with generally accepted government auditing standards.

We provided a briefing on the results of our work to staff of the House Committee on Education and the Workforce on May 15, 2003. We provided additional information in a second briefing on June 6, 2003. This report formally conveys the information provided during those briefings.

In summary, we found that data from Head Start compliance reviews conducted during 2000-02 indicated that most programs met performance standards for overall curriculum and for cognitive and language development. Of all 1,532 programs in HHS's 10 regions, HHS determined that the highest percent found out of compliance with any one of seven specific performance standards for cognitive and language development was 10 percent. Among the programs cited for compliance issues related to these standards, the areas most in need of improvement included (1) using classroom activities and materials that were sufficiently adapted to each child's developmental level and (2) using continuous observation and assessment to support each child's instruction in cognitive and literacy skills.

For the most part, Head Start teachers reported that children were in programs that used a specific curriculum or combinations of curricula; in 1998 and 2000, the largest percentages were in programs that used either High Scope or Creative Curriculum. Different methodologies for each survey precluded making comparisons over time. In 2000, children were more likely to listen to stories for which they see print, to learn about prepositions, new words, the conventions of print and letters, and to retell stories on a daily or almost daily basis, than to experience other language development activities, such as working on phonics, writing their name, or learning about rhyming words and word families.

Of those who had a mentor, teachers of about two-thirds of Head Start children received mentoring visits, weekly or bi-weekly. In 2000, teachers of an estimated 78 percent of Head Start children used individual assessments in their small group instruction and in overall curriculum planning. Almost 90 percent of Head Start children received individual assessments in cognitive and language development. About half were assessed in mathematics and emergent literacy. The children received individual assessments at least once a year. 
We provided a draft of this report to HHS for review and comment. HHS indicated that it had no general comments but provided written technical comments, which we incorporated as appropriate.

We are sending copies of this report to relevant congressional committees and other interested parties. We also will make copies available to others upon request. This report will also be available on GAO's Web site at http://www.gao.gov.

If you or your staff have any questions about this report, please contact me or Betty Ward-Zukerman at (202) 512-7215. Sara Edmondson, Luann Moy, Christopher Moriarity, and Elsie Picyk also made key contributions to this report.

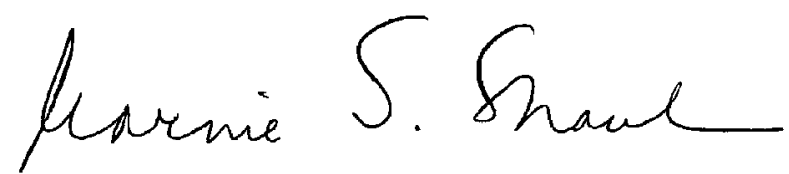

Marnie S. Shaul

Director, Education, Workforce, and

Income Security Issues 


\section{Appendix I: Congressional Briefing Slides: Head Start}

Briefing for Congressional Requesters

May 15, and June 6, 2003

HEAD START: Curriculum Use and Individual Child Assessment in Cognitive and Language Development 
Introduction

The 1998 amendments to the Head Start Act provided for updating performance standards to ensure that Head Start children leave the program ready for school. Head Start's performance standards for education and early childhood development require that programs' curricula support each child's cognitive and language development, including emergent literacy skills. ${ }^{1}$

In preschool children, cognitive and language development refer to advances in basic abilities in thinking and speaking. Skills in emergent literacy are the precursors to reading, such as learning the letters of the alphabet.

As reauthorization of Head Start approached, you asked us to determine the progress of local Head Start programs in meeting the performance standards for children's cognitive and language development and to describe their use of curricula, mentoring for teachers, and child assessments to foster children's development.

${ }^{1}$ Pub. L. 105-285, Title I, Sec. 108 (amending sec. 641A of the Head Start Act). 


\section{Key Questions}

1. To what extent have Head Start programs made progress in meeting performance standards for cognitive and language development since they took effect in January 1998 ?

2. To what extent has local Head Start programs' use of curricula changed since the performance standards for children's cognitive and language development were issued?

3. To what extent have local Head Start programs used teacher mentoring and individual child assessments to support curriculum planning? 


\section{Scope and Methodology}

We determined what progress has been made in meeting the new standards by analyzing data from the Head Start Monitoring and Tracking System (HSMTS), an automated database that quantifies and tabulates the results of Head Start on-site compliance reviews.

We examined local Head Start programs' use of curricula and individual child assessment practices by:

- Analyzing data from the Department of Health and Human Services' (HHS) Family and Child Experiences Survey (FACES). FACES is a series of longitudinal surveys of nationally representative samples of Head Start children. Employing multiple data collection instruments, the survey includes assessments of children, interviews with their parents, observation of classrooms, and interviews with teachers. We used data from the spring 1998 and fall 2000 teacher interviews, which contained information about curriculum use, teachers, and child assessment practices. 


\section{Scope and Methodology (continued)}

- Producing weighted estimates from the 1998 and 2000 FACES teacher interview data using child weights developed by the FACES project team. A weight is the factor we used to make estimates for the Head Start child population from the FACES sample data. Because we were analyzing data for both 1998 and 2000, we used the same type of weights for both years.

- Obtaining margins of error for estimates using FACES data at the 95 percent confidence level.

- Interviewing officials responsible for Head Start compliance reviews in 9 of HHS's 10 regional offices about Head Start programs' curriculum practices.

- Analyzing HHS's 2002 Program Information Report data regarding use of curricula and child assessment instruments.

We conducted our work between February and June 2003 in accordance with generally accepted government auditing standards. 


\section{Scope and Methodology (continued)}

Limitations

- We did not review Head Start's performance standards, apart from identifying those related to cognitive and language development, or independently assess compliance by Head Start programs.

- Using existing administrative and FACES data, our review provides information about the Head Start program at the national level, focusing on the 50 states and the District of Columbia. Our review does not examine Head Start programs for migrants, Native Americans, or the Early Head Start program.

- The FACES samples were designed to be nationally representative of Head Start children. Teachers were included in the survey sample if they were teachers of sampled children, yielding a probability sample. However, because the probability sample of teachers that resulted also yielded high standard errors, our estimates from the teacher interview data were less precise than would have been true had the sample been designed primarily to collect data about teachers. 


\section{Summary of Results}

- Data from Head Start compliance reviews indicated that most programs met performance standards for overall curriculum and for seven specific standards for cognitive and language development.

- For the most part, Head Start children were in programs that used a specific curriculum or combinations of curricula; in 1998 and 2000, the largest percentages of Head Start children were in programs that used either High Scope or Creative Curriculum. However, because the surveys in each time period used different methodologies, we could not determine if these percentages represented an actual change over time. The FACES data indicated that, in each time period, most Head Start children had teachers who reported offering basic cognitive or language development activities daily or almost daily, but provided no additional information on how the curricula were implemented.

- Of those who had a mentor, teachers for about two-thirds of Head Start children reported being observed by a mentor, once every week or every 2 weeks. Teachers of an estimated 78 percent of Head Start children reported using information from individual assessments for small group instruction and in overall curriculum planning. Almost 90 percent of Head Start children were assessed in cognitive and language development; about half were assessed in mathematics and emergent literacy. 


\section{Background}

- Head Start programs are administered locally but must comply with federal performance standards in a number of categories, such as education and early childhood development, child health and safety, and family and community partnerships. The standards for education and early childhood development pertain to curriculum and are designed to foster school readiness in all areas of social competence, including social, emotional, and physical, as well as cognitive. Our review focused on seven of the curriculum standards for children's cognitive and language development.

- HHS regional offices make on-site inspections to monitor programs' performance in meeting all performance standards. Inspection teams monitor approximately one-third of the programs each year. 


\section{Background (continued)}

- Head Start's performance standards for cognitive and language development are based on concepts, such as emergent literacy, that have their roots in behavioral and social science research on child development:

- Cognitive development refers to advances in a child's ability to develop ideas and theories about how things work, that is, the general ability to reason.

- Language development refers to a child's progress in learning language, including grammar, the sounds of speech and vocabulary.

- Emergent literacy refers to the theory that developing the ability to read begins early in a child's life, rather than when a child starts school. It includes the skills, knowledge, and attitudes that are considered forerunners to reading and writing, including recognizing the names of the letters of the alphabet, scribbling, recognizing that the print in books is what is read, paying attention to the sounds in words, and connecting stories to life experiences. ${ }^{2}$

${ }^{2}$ Since 1998, the National Research Council has examined the research on early childhood learning and development in several comprehensive reviews that discuss these concepts in greater detail. National Research Council, Starting Out Right: A Guide to Promoting Children's Reading Success, Committee on Prevention of Reading Difficulties in Young Children, M.S. Burns, P. Griffin, and C.E. Snow, eds. (Washington, DC: National Academy Press, 1999); National Research Council, How People Learn: Mind, Brain, Experience, School-Expanded Edition, Committee on Developments in the Science of Learning, J.D. Bransford, A.L. Brown, and R. R. Cocking, eds. (Washington, D.C.: National Academy Press, 2001); and National Research Council, Eager to Learn, Committee on Early Childhood Pedagogy, B. T. Bowman, M.S. Donovan, and M. Susan Burns, eds. (Washington, D.C.: National Academy Press, 2001). 

Language Development

- Standard 1304.21 (a) (4)-Grantee and delegate agencies must provide for the development of each child's cognitive and language skills by

(i) using a variety of strategies,

(ii) providing for creative self-expression,

(iii) promoting interaction and conversation with others, and

(iv) providing materials and activities adapted to each child.

- Standard 1304.21 (c) (1)-Grantee and delegate agencies, in collaboration with the parents, must implement a curriculum to

(i) support each child's individual pattern of development and learning and

(ii) develop each child's cognitive, literacy, and mathematical skills. 
Head Start Performance Standards for Cognitive and Language Development (continued)

- Standard 1304.21 (c) (2)-Staff must use a variety of strategies to promote and support children's learning and developmental progress based on the observation and ongoing assessment of each child. 


\section{Background (continued)}

- The curriculum Head Start programs use must meet the definition for curriculum in Head Start performance standards. ${ }^{3}$ Programs may develop their own curriculum, adopt, or adapt any existing package. Two widely used existing curricula are High Scope and Creative Curriculum.

- Head Start's performance standards define curriculum as a written plan that includes: (1) goals for children's development and learning, (2) the experiences through which children will achieve the goals, (3) what staff and parents do to help children achieve the goals, and (4) the materials needed to support the implementation of the curriculum. 


\section{Key Features of Two Curricula-High Scope and Creative Curriculum}

\begin{tabular}{lll}
$\begin{array}{l}\text { Curriculum } \\
\text { features }\end{array}$ & High Scope & Creative Curriculum \\
\hline $\begin{array}{l}\text { Teaching and } \\
\text { learning theory }\end{array}$ & $\begin{array}{l}\text { Encourages children to pursue their own interests } \\
\text { and goals. Teaching strategies balance child and adult initiation. }\end{array}$ & $\begin{array}{l}\text { Balances teacher-directed and child-initiated learning, } \\
\text { emphasizing responding to children's learning styles and } \\
\text { building on their interests. }\end{array}$ \\
\hline $\begin{array}{l}\text { Curriculum } \\
\text { framework }\end{array}$ & $\begin{array}{l}\text { Fifty-eight key experiences for preschool children grouped into } \\
\text { 10 categories: creative representation, language and literacy, } \\
\text { initiative and social relations, movement, music, classification, }\end{array}$ & $\begin{array}{l}\text { Five major areas: how children develop and learn, the } \\
\text { learning environment, the content areas children learn, the } \\
\text { teacher's role, and the family's role. Six content areas: } \\
\text { literary, math, science, social studies, arts, technology, and } \\
\text { seriation, number, space, and time. } \\
\text { classroom interest areas: blocks, dramatic play, toys and } \\
\text { games, art, library, discovery, sand and water, music and } \\
\text { movement, cooking, computers, and outdoors. }\end{array}$ \\
\hline $\begin{array}{l}\text { Parent } \\
\text { involvement }\end{array}$ & $\begin{array}{l}\text { Encourages parent participation in the classroom } \\
\text { and fosters home-school communication. }\end{array}$ & $\begin{array}{l}\text { Guides teachers in developing a relationship with the child's } \\
\text { family. }\end{array}$ \\
\hline Assessment & $\begin{array}{l}\text { Using the Child Observation Record, a teacher or observer } \\
\text { assesses a child's behavior in } 6 \text { areas: initiative, social relations, } \\
\text { creative representation, music and movement, language and } \\
\text { literacy, and logic and mathematics. }\end{array}$ & $\begin{array}{l}\text { Includes a Creative Curriculum Developmental Continuum } \\
\text { for ages 3-5, which defines and measures a sequence of } \\
\text { steps a child is expected to take toward milestones in } \\
\text { socioemotional, physical, cognitive, and language } \\
\text { development. }\end{array}$ \\
& &
\end{tabular}

Sources: GAO summary of curriculum publishers' documentation. 


\section{Overall, HHS Finds Most Programs in Compliance with Curriculum Standards}

- By 2002, HHS had determined that at least 45 percent of all 1,532 programs in HHS's 10 regions were rated as having "no findings" in curriculum-related areas during on-site inspections, meaning that the programs were in full compliance with Head Start's overall performance standards for curriculum. ${ }^{5}$ The remaining programs had at least one finding.

- In 2002, HHS found that no more than 10 percent of the programs reviewed in any geographic region that year had serious or significant areas of noncompliance with overall standards for curriculum. 
Overall, HHS Finds Most Programs in Compliance with Curriculum Standards (continued)

- Three percent of the programs reviewed in 2002 were rated deficient with regard to the overall performance standards for curriculum. ${ }^{6}$

- Deficiencies must be corrected immediately or within a year, pursuant to a written quality improvement plan.

- Deficiencies not corrected within the specified time frame will lead to termination of the grant or denial of refunding. 

Cognitive and Language Development Standards

- Of the 1,532 programs reviewed during 2000-02, HHS determined that the highest percent found out of compliance with any one of the seven specific performance standards for cognitive and language development was 10 percent.

- Programs were found out of compliance most often for:

- not using classroom activities and materials sufficiently adapted to children's varied development and

- not making continuous observation and assessment of each child's progress. 


\section{Head Start Children Were in Programs That Used a Specific Curriculum}

The FACES data did not allow us to determine change over time, but did permit us to describe Head Start curricula at two points in time.

- In large part, Head Start teachers reported that children were in programs that used a specific curriculum or combinations of curricula. In 1998, an estimated 54 percent of Head Start children were in programs that used either High Scope or Creative Curriculum, while in 2000, an estimated 58 percent of the children were in programs that used one or the other curriculum. However, because the surveys in each time period used different methodologies, we could not determine if these percentages represented an actual change.

- In each time period, more than 40 percent of the children were in classes that used other curricula or combinations of curricula. ${ }^{7}$ In 1998, some combinations included High Scope and Creative Curriculum.

${ }^{7}$ HHS's Administration for Children and Families has issued Head Start FACES (2000): A Whole-Child Perspective on Program Performance, Fourth Progress Report, which includes analyses of Head Start curricula that were beyond the scope of this study. See http://www.acf.hhs.gov/programs/core/ 


\section{In 1998, the Largest Percentages of Head Start Children Were in Classes That Used High Scope or Creative Curriculum}

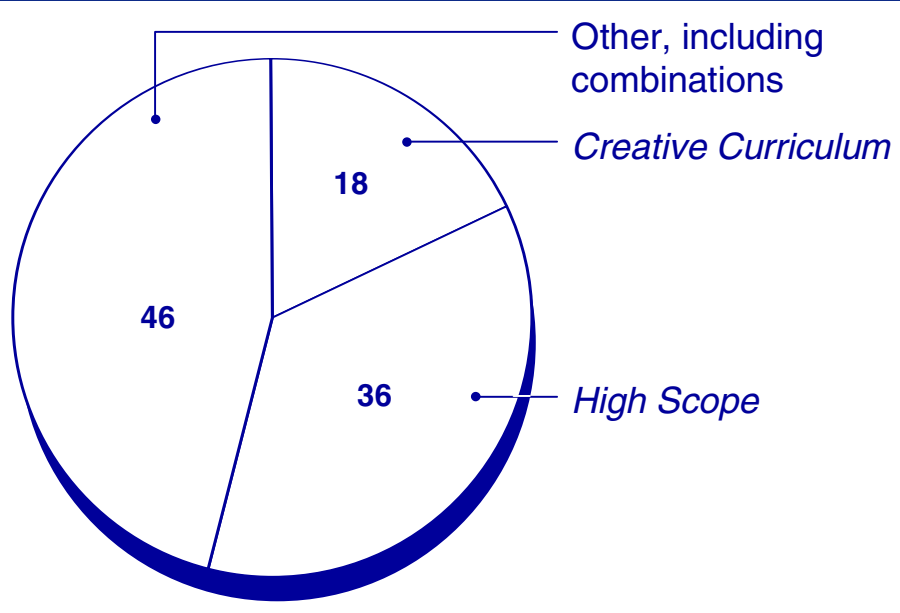

Sources: 1998 FACES teacher interview data, GAO analysis.

Note: The survey question in the 1998 teacher interview that provided these data asked FACES respondents to identify the name of their principal curriculum. Because many respondents answered the question in a way that indicated they used more than one principal curriculum, we recoded the responses. We interpreted the use of more than one principal curriculum as the use of combinations of curricula. Some combinations included High Scope and Creative Curriculum.

The percentages are based on sample data and have at most, a plus or minus 13 percent margin of error. 


\section{In 2000, the Largest Percentages of Head Start Children Also Were in Classes That Used High Scope or Creative Curriculum}

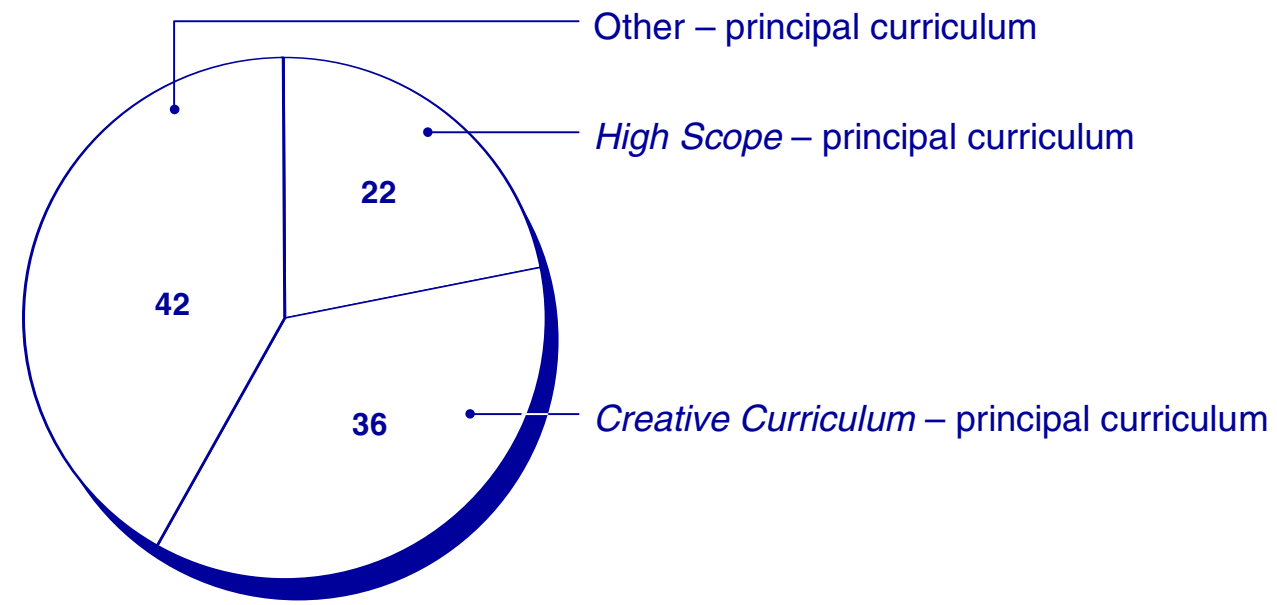

Sources: 2000 FACES teacher interview data, GAO analysis.

Note: The survey question in the 2000 teacher interview that provided these data asked FACES respondents to identify the name of their principal curriculum. Respondents answered the question in a way that indicated the one principal curriculum they used. The percentages above are based on sample data and have at most, a plus or minus 15 percent margin of error.

Responses to HHS's 2002 Program Information Report (PIR) indicated that 45 percent of Head Start programs used Creative Curriculum and 18 percent used High Scope. The question in the PIR concerning the type of curriculum used was open-ended. These percentages represent responses by programs that reported simply "Creative Curriculum" or "High Scope". 
Teachers Reported That Head Start Children Have Been Exposed to a Variety of Cognitive and Language Development Activities

- The FACES data included no detailed information on the implementation of individual curriculum packages in 1998 and 2000, but some information on the activities supporting cognitive development that children experienced was available. However, because HHS's FACES project team changed and expanded the FACES interview questions in 2000, to collect more detailed information on children's exposure to activities that foster emergent literacy, these data also did not allow us to determine change over time.

- In both time periods, most Head Start children had teachers who reported offering basic cognitive and language development activities daily or almost daily. 
In 1998, Teachers Reported That over 90 Percent of Head Start Children Experienced Several Basic Cognitive Development Activities Daily or Almost Daily

\begin{tabular}{lc} 
Activity offered by teacher & $\begin{array}{c}\text { Percentage } \\
\text { of children }\end{array}$ \\
\hline $\begin{array}{l}\text { Building with blocks or doing other } \\
\text { construction work }\end{array}$ & 96 \\
\hline Reading stories & 95 \\
\hline $\begin{array}{l}\text { Solving puzzles and playing with } \\
\text { geometric forms }\end{array}$ & 93 \\
\hline Learning numbers or counting & 92 \\
\hline Learning letters & 68 \\
\hline
\end{tabular}

- Teachers reported that over 90 percent of Head Start children experienced block building, story reading, solving puzzles, and learning numbers daily or almost daily. A smaller proportion learned letters that often. 

Were Exposed to a Variety of Language Development Activities Daily or Almost Daily

\begin{tabular}{lc}
\hline Children's classroom activity & $\begin{array}{c}\text { Percentage } \\
\text { of children }\end{array}$ \\
\hline Listening to stories for which they see print & 89 \\
\hline Discussing new words & 76 \\
\hline Learning about common prepositions & 75 \\
\hline Learning about the conventions of print & 68 \\
\hline Learning letters & 67 \\
\hline Retelling stories & 60 \\
\hline Dictating stories & 52 \\
\hline Working on phonics & 48 \\
\hline Writing their name & 43 \\
\hline Learning about rhyming words and word families & 41 \\
\hline Writing letters & 33 \\
\hline Listening to stories for which they do not see print & 29 \\
\hline
\end{tabular}

- Children were more likely to listen to stories for which they see print, to learn about new words, prepositions, the conventions of print and letters, and to retell stories, on a daily or almost daily basis, than to experience the other activities.

Sources: 2000 FACES teacher interview data, GAO analysis. There were no items in the 2000 FACES teacher interview concerning classroom activities that fostered general reasoning and numerical skills.

Note: The percentages are based on sample data and have at most, a plus or minus 10 percent margin of error. Differences in the percentages greater than 25 percent are statistically significant. Differences less than 10 percent are not statistically significant. 


\section{Regional Officials Reported Some Changes in Use of Curricula}

- According to officials in 8 of HHS's 10 regional offices, use of curriculum by programs in several regions has changed since 1998. They reported that:

- More programs are using published curricula. Programs have found that commercially produced curricula make it easier for them to measure child outcomes. They also use supplementary curricula that they adapt to the commercial curricula.

- Programs are selecting curricula that include assessment tools that also can help measure outcomes. ${ }^{8}$

- Programs are implementing their curricula with a more structured, sequenced set of classroom activities.

${ }^{8}$ Responses to HHS's 2002 Program Information Report (PIR) indicate that, for on-going child assessment, the assessment instruments developed by publishers of Creative Curriculum and High Scope were used by the largest percentage of programs. Of programs 


\section{In 2000, Teachers of Most Head Start Children Reported Receiving Mentoring Support}

- Teachers of about two-thirds of Head Start children reported being observed by a mentor, who provided feedback, guidance, and training.

- Of children whose teachers have a mentor, the teachers of about 60 percent received mentoring visits once every week or every 2 weeks. Teachers of the remainder received mentoring visits about once a month or less often.

- About half of Head Start children had teachers who acted as a mentor for other teachers and trainees. ${ }^{9}$ 

Monitored Their Individual Progress

- About 90 percent of Head Start children had teachers who reported maintaining records of progress on each child.

- These individual records usually included samples of the child's work, checklists, or rating scales that indicated the child's skill level or notes from observations of the child's progress. 


\section{In 2000, Individual Progress of about Two-thirds of Head Start Children Was Tracked Using a Written System}

\begin{tabular}{lc}
\hline & $\begin{array}{c}\text { Percentage of } \\
\text { children whose } \\
\text { teachers use the } \\
\text { child } \\
\text { assessment } \\
\text { approach }\end{array}$ \\
\hline $\begin{array}{l}\text { Whild assessment approach } \\
\text { child's progress on chart, grid, or } \\
\text { series of scales }\end{array}$ & 67 \\
\hline Each child is observed during class \\
and notes are kept
\end{tabular}

- About two-thirds of Head Start children whose teachers conduct individual assessments were assessed using a written system that tracks each child's progress on a chart, grid, or series of scales.

- Teachers of an estimated 30 percent of Head Start children who were assessed used recorded observations of the children during class as the assessment method.

- Teachers of an estimated 3 percent of Head Start children observed their behavior but kept no records.

Sources: 2000 FACES teacher interview data, GAO analysis.

Note: The percentages are based on sample data and have at most, a plus or minus 9 percent margin of error. The differences among all percentages are statistically significant. 


\section{In 2000, Almost 90 Percent of Head Start Children Received Individual Assessments in Cognitive and Language Development}

Areas of child development

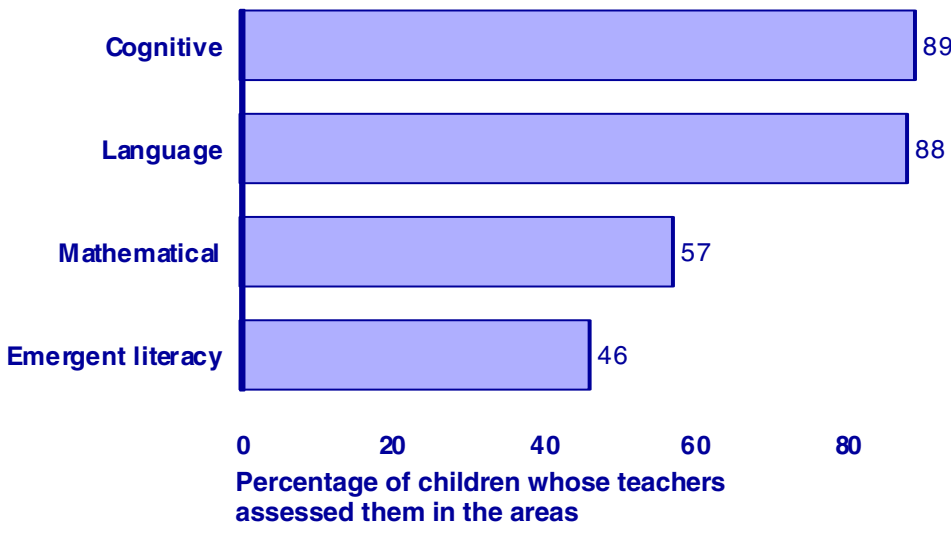

- Most Head Start children received individual assessments in cognitive and language development. ${ }^{10}$

- More than half of Head Start children were assessed in mathematical areas of development and almost half were assessed in emergent literacy.

Sources: 2000 FACES teacher interview data, GAO analysis.

Note: The percentages are based on sample data and have at most, a plus or minus 12 percent margin of error. The differences among the percentages for the cognitive, language, emergent literacy, and mathematical areas of development that are greater than 20 percent are statistically significant. Differences less than 12 percent are not statistically significant.

${ }^{10} \mathrm{Head}$ Start children's individual assessments cover a range of areas, including physical growth, motor, social and emotional skills and FACES collects information on assessments in these areas. We have reported findings only for the cognitive, language, emergent literacy, and mathematical areas of development because those areas were the focus of our review. Although High Scope and Creative Curriculum include assessment instruments, the FACES data did not identify the instruments that were used to conduct these assessments. 
Head Start Children Received Individual Assessments at Least Once a Year in 2000

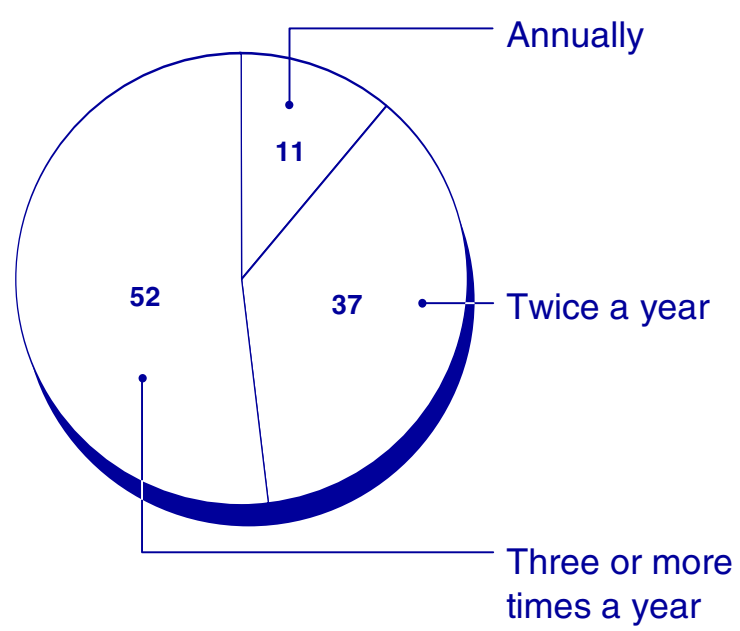

- About half of Head Start children received individual assessments three or more times a year and about half received assessments once or twice a year.

Sources: 2000 FACES teacher interview data, GAO analysis.

Note: The percentages are based on sample data and have at most, a plus or minus 11 percent margin of error. The differences between the percentage for annual assessment and the percentages for twice a year and three or more times a year are statistically significant. 


\section{In 2000, Individual Assessment Results Were Used for Small Groups and Overall Curriculum Planning}

\section{Use of individual child assessment information}

Used both in selecting small groups and in overall curriculum planning

Used to select small groups of children, by skill level, for specific learning activities

Used to select the appropriate level for all instructional activities or in overall curriculum planning

Information was recorded but not

used for planning
Percentage of

Head Start children

\section{8}

11

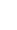

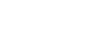

10 (1)
- Teachers of an estimated 78 percent of Head Start children used the information from individual assessments to select small groups, by skill level, for specific learning activities, and in overall curriculum planning.

Sources: 2000 FACES teacher interview data, GAO analysis.

Note: The percentages are based on sample data and have at most, a plus or minus 9 percent margin of error. The differences among all but two sets of percentages are statistically significant. The difference between information was not recorded and used to select the appropriate level, and the difference between used to select small groups and used to select the appropriate level were not statistically significant. 


\section{GAO's Mission}

The General Accounting Office, the audit, evaluation and investigative arm of Congress, exists to support Congress in meeting its constitutional responsibilities and to help improve the performance and accountability of the federal government for the American people. GAO examines the use of public funds; evaluates federal programs and policies; and provides analyses, recommendations, and other assistance to help Congress make informed oversight, policy, and funding decisions. GAO's commitment to good government is reflected in its core values of accountability, integrity, and reliability.

\section{Obtaining Copies of GAO Reports and Testimony}

The fastest and easiest way to obtain copies of GAO documents at no cost is through the Internet. GAO's Web site (www.gao.gov) contains abstracts and fulltext files of current reports and testimony and an expanding archive of older products. The Web site features a search engine to help you locate documents using key words and phrases. You can print these documents in their entirety, including charts and other graphics.

Each day, GAO issues a list of newly released reports, testimony, and correspondence. GAO posts this list, known as "Today's Reports," on its Web site daily. The list contains links to the full-text document files. To have GAO e-mail this list to you every afternoon, go to www.gao.gov and select "Subscribe to e-mail alerts" under the "Order GAO Products" heading.

\section{Order by Mail or Phone}

The first copy of each printed report is free. Additional copies are $\$ 2$ each. A check or money order should be made out to the Superintendent of Documents. GAO also accepts VISA and Mastercard. Orders for 100 or more copies mailed to a single address are discounted 25 percent. Orders should be sent to:

\section{U.S. General Accounting Office \\ 441 G Street NW, Room LM \\ Washington, D.C. 20548}

$\begin{array}{lll}\text { To order by Phone: } & \text { Voice: } & \text { (202) } 512-6000 \\ & \text { TDD: } & (202) 512-2537 \\ & \text { Fax: } & \text { (202) } 512-6061\end{array}$

\section{To Report Fraud, Waste, and Abuse in Federal Programs} Contact:

Web site: www.gao.gov/fraudnet/fraudnet.htm E-mail: fraudnet@gao.gov Automated answering system: (800) 424-5454 or (202) 512-7470 